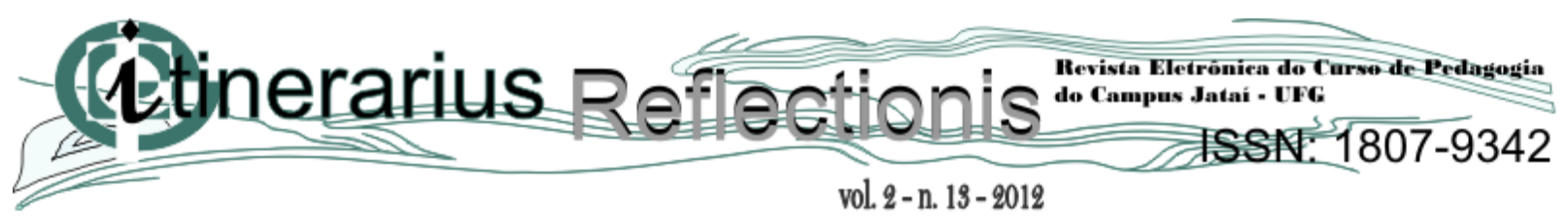

\title{
UM MODELO DE ROLE-PLAYING GAME (RPG) PARA O ENSINO DOS PROCESSOS DA DIGESTÃO
}

\author{
Antônio Alves de Oliveira Neto. Acadêmico do curso de \\ licenciatura em Ciências Biológicas - Universidade \\ Federal de Goiás, Campus Jataí, Ciências Biológicas - \\ tonyton10@hotmail.com
}

Sandra Aparecida Benite-Ribeiro. Docente do curso de ciências Biológicas - Universidade Federal de Goiás, Campus Jataí, Ciências Biológicas

\begin{abstract}
RESUMO: O jogo didático representa uma alternativa para auxiliar no processo de ensinoaprendizagem, pois favorece a construção do conhecimento pelo aluno. O Role-Playing Game (RPG) tem sido apontado como importante material pedagógico, pois incentiva a cooperação e a utilização do saber prévio dos estudantes para a construção de novos conhecimentos. No presente artigo apresentamos um jogo de RPG elaborado por estudantes do curso de Licenciatura em Biologia e a avaliação dos resultados de sua aplicação aos estudantes do ensino superior, médio e fundamental da rede pública de ensino. Os objetivos do estudo foram elaborar um jogo que pudesse mediar a aprendizagem, diversificar e avaliar a transmissão do conhecimento, além de testar um método de ensino para que os futuros professores de Ciências e Biologia pudessem utilizar em sua prática profissional. Para a formulação do RPG foi criada uma aventura dentro do corpo humano com 25 questões a respeito de fisiologia do sistema digestório e vários desafios aos jogadores. O jogo foi aplicado nas aulas práticas de Fisiologia Humana Básica aos estudantes do ensino superior e nas aulas de Ciências e de Biologia, aos estudantes do ensino fundamental e médio, respectivamente. Os alunos do curso de Biologia aprovaram o modelo didático e perceberam sua eficácia ao associar a imaginação, a cooperação no trabalho em grupo e a forma como pode ser utilizado para ensinar e avaliar os conhecimentos adquiridos. Os estudantes do ensino fundamental e médio perceberam a importância da cooperação, demonstraram grande interesse pelo jogo e motivação com o conteúdo abordado durante a prática. Concluindo-se, consideramos que o jogo de RPG educativo elaborado no presente trabalho atingiu o objetivo de criar um modelo didático para o ensino por métodos lúdicos, auxiliando no processo de aprendizagem do conteúdo e na sua avaliação. Ressaltamos que RPG elaborado no presente estudo pode ser adaptado para interesses específicos dos docentes em relação à série que será aplicado e à realidade dos estudantes.
\end{abstract}

Palavras-chave: Modelo. Jogo didático. Ensino-aprendizagem.

ABSTRACT: The game can be an educational alternative in the teaching-learning process, since it facilitates the construction of knowledge by the student. The Role-Playing Game (RPG) has been suggested as an important pedagogical material, since it encourages the 
cooperation and the use of the prior knowledge of students to construct new skills. In this paper we presents an RPG game developed by students Biology and the evaluation of the results of its application to higher, fundamental and medium students of public education. The objectives of the study were to elaborate a game to mediate learning, diversify and evaluate the transmission of knowledge, and to test a method of teaching, so that future biology teachers could use in their professional practice. For the formulation of RPG an adventure was created inside the human body with 25 questions about the physiology of the digestive system and several challenges to players. The game was applied in practical classes of Basic Human Physiology to students of higher education and in science and biology classes to students of elementary and secondary education, respectively. The students of Biology approved the didactic model, recognized its effectiveness by combining imagination, cooperation in group work and how they can be used to teach and assess the knowledge acquired. Students in elementary and middle school recognized the importance of cooperation, showed great interest in the game and motivation with the content covered during practice. Concluding, we believe that the educational role-playing game developed in this study achieved the goal of creating a model for didactic teaching methods, assisting in the learning of applied content and in the evaluation of the learning. In addition, the RPG elaborated in the present study can be modified according to the needs of professor and students.

Key-words: Model, educational game, teaching-learning

\section{Introdução}

A aprendizagem e seus processos têm gerado uma preocupação para pesquisadores da área de que não existe uma maneira pronta para resolução deste problema. A compreensão dos mecanismos de aprendizagem e os aspectos desse processo são passos importantes para o planejamento e a implantação de práticas, que devem ser exploradas por estratégias metodológicas, de forma a propiciar elementos para aprendizagem significativa e um ensino de boa qualidade (Cabrera, 2006).

Atualmente tem sido proposto que o papel de protagonista do processo de aprendizagem deve ser assumido pelos estudantes, dentro de uma perspectiva do sujeito construtor do próprio conhecimento. Assim, atividades que promovam a participação ativa dos alunos, e que os envolvam situações problemáticas e motivadoras, certamente representarão contribuições na aprendizagem significativa dos estudantes (Ferreira et al, 2003). 


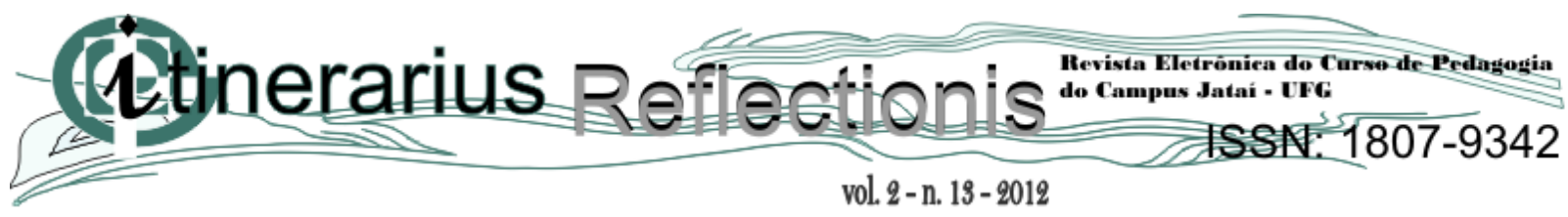

Os materiais didáticos são ferramentas fundamentais para os procedimentos de ensino e de aprendizagem, sendo que o jogo didático representa uma importante alternativa para auxiliar em tais processos, pois favorece a construção do conhecimento pelo aluno. Assim, a utilização dos jogos didáticos pode ser considerada atraente, uma vez que tem capacidade de preencher muitas lacunas deixadas durante o processo de transmissão e recepção de conhecimento. Além disso, o jogo favorece o trabalho coletivo, a socialização de conhecimentos prévios e de sua utilização para a construção de novos conhecimentos (Campos et al, 2010).

Adicionalmente, segundo Campos e colaboradores (2010), a assimilação e a aprendizagem de conhecimentos são facilitadas quando tomam a forma aparente de atividade lúdica, haja vista que os estudantes demonstram entusiasmo quando lhes é proposto aprender de uma maneira mais interativa e divertida, o que pode resultar em um aprendizado mais significativo. Nesta perspectiva, o jogo ganha um espaço como ferramenta ideal da aprendizagem, motivando o aluno, desenvolvendo diferentes níveis de experiência pessoal e social, auxiliando na construção de novas descobertas e desenvolvendo sua personalidade. Este instrumento pedagógico leva o professor à condição de condutor, estimulador e avaliador da aprendizagem.

Diante da constante busca de criar novas formas de ensino, que favoreçam o envolvimento ativo do aluno no processo de aprendizagem, utilizamos o Role-Playing Game (RPG) que numa tradução simples seria próximo de "jogo de interpretação de papeis", como material pedagógico no ensino de Biologia. O jogo teve como objetivos ensinar, diversificar, avaliar a transmissão do conhecimento e testar uma nova metodologia a ser trabalhada em sala de aula.

O Role-Playing Game (RPG) é um jogo de contar histórias, sendo que os ouvintes se tornam agentes ativos movimentando as personagens criadas por eles mesmos. É um tipo de jogo no qual os jogadores assumem papéis de personagens e criam narrativas colaborativamente. O progresso de um jogo se dá de acordo com um sistema de regras prédeterminadas, dentro das quais os jogadores podem improvisar livremente. Aplicado num ambiente escolar é um jogo muito peculiar, de caráter socializador, cooperativo e 
interdisciplinar, ou seja, não há disputa entre adversários, mas colaboração para a vivência de aventuras em um mundo imaginário. O RPG tem seu uso amplamente incentivado pelo Ministério da Educação (MEC) como método de ensino. É usado para aguçar a cooperação e o raciocínio lógico dos estudantes. Possui regras que o definem e que orientam o que os personagens podem ou não fazer (Amaral, 2008; Maike et al, 2011).

No RPG podemos definir dois tipos de jogadores, o primeiro é o mestre, que cria a história e julga as ações de todos os personagens do jogo. O outro é o personagem que criará uma figura dramática fictícia, seguindo as regras do sistema escolhido por seu grupo, ou impostas pelo mestre, além de controlar seu personagem pelas aventuras do jogo (Amaral, 2008). O RPG permite que o mestre crie situações a decorrer do jogo e mesmo com um jogo planejado com um final pré-estabelecido, algo novo pode ocorrer e mudar os rumos da história.

\section{Desenvolvimento}

Antes de iniciar o RPG

A história utilizada para o RPG foi elaborada por uma turma de alunos do curso de graduação em Ciências Biológicas da Universidade Federal de Goiás, na disciplina de Fisiologia Humana Básica, com o objetivo de criar novas estratégias para o ensino de biologia na segunda fase do Ensino Fundamental e no Ensino Médio.

Para formulação do RPG foi criada uma aventura para narrar os acontecimentos durante o jogo, as ações que poderiam ser desenvolvidas pelos jogadores, os desafios e as possibilidades que dependeriam da opção dos sujeitos . O presente RPG foi elaborado para ser jogado com dois e no máximo cinco participantes.

Uma das regras básicas para o desenvolvimento do jogo é que o mestre representa a autoridade máxima do jogo, toda e qualquer situação que não esteja pré-estabelecida, deverá ser resolvida de imediato pelo mestre para não prejudicar o jogo, sendo que os jogadores deverão acatar sem contra argumentação. Decisões que necessitem ser tomadas através de 
vol. 2-n. $13-2012$

lances do dado ou pela opção dos jogadores obedecerão a um cálculo que corresponderá ao desafio proposto, que será mais bem explicado durante o jogo descrito adiante. Este cálculo poderá ou não ser informado pelo mestre, porém ele deve dizer o valor mínimo a ser obtido em cada rodada (ver instruções no jogo adiante). As respostas aos desafios deverão ser resultantes da cooperação e o mestre aceitará apenas uma resposta.

Ao final o mestre poderá fornecer aos jogadores o número de respostas e desafios respondidos corretamente. A cada resposta certa pode se aplicar o valor de 0,4 pontos para 25 aplicadas, num total de 10 pontos.

Para a aplicação do jogo, foram necessários um aparelho de multimídia e um computador para exibição das imagens que auxiliaram no processo de imaginação, um dado, lápis e folhas de papel para cada um dos participantes.

Iniciando o jogo:

\section{Primeira etapa}

Instruções dadas pelo mestre para a criação dos personagens e introdução da narrativa utilizada para o jogo:

Ano 2558, o sistema Solar foi destruído pelo cometa FUNDEAR (que significa ancorar), que se chocou com o sol e causou uma instabilidade à estrela. Este evento acabou por destruir todo o sistema solar. Apesar disso, como a trajetória do cometa foi descrita 100 anos antes do acontecimento, a humanidade teve tempo para procurar um novo local para viver. Este local se localiza na galáxia de CORISTA, pois a vista dela do espaço lembrava uma dança, e o seu planeta que possibilitou a sobrevivência dos seres humanos. O planeta foi denominado de NÁCAR, pois tem uma aparência branca, brilhante, iridescente. O mesmo possui apenas um oceano e a maior parte das terras emersas, onde a população sobrevivente se estabeleceu, é árida. Sete naves partiram cada uma com 1.500 pessoas a bordo. Atracaram em NÁCAR em 2493 e fundaram a cidade de "TERRA" em lembrança ao passado.

Desde então muito aconteceu quanto à tecnologia dos seres humanos. A mais recente foi a do reducionismo de partículas, que possibilita reduzir qualquer matéria a uma 
vol. 2-n. 13 - 2012

escala microscópica. Criada pelo professor Dr. Zoddi, visa, dentre outras coisas, conhecer o corpo humano, e para isso conta com uma equipe de pesquisadores, que farão uma viagem pelo corpo humano após teste mais completos e a presença de voluntários para a experiência.

O mestre pede aos jogadores que preencham a ficha (Figura 1), a lápis, com as características de seus personagens. O objetivo principal da ficha é auxiliar no processo criativo do personagem e na integração dos participantes no contexto da história. Cada jogador deve distribuir 10 pontos entre qualidades, cinco pontos entre defeitos e escolher um medo.

Os jogadores podem escolher seus nomes e país de origem na terra antiga. Com a ficha pronta inicia-se a próxima etapa. Além disso, o mestre pode pedir aos jogadores que nomeiem um líder para dar as respostas dos desafios.

Nome do personagem:

Origem:

Qualidades:

Alegria

Responsabilidade

Inteligência

Força

Habilidade

Calma

Figura 1: Ficha dos personagens do RPG.

Fobia de perder

\section{Defeitos:}

Agressividade

Orgulho

Traidor

Irresponsabilidade

Azar 


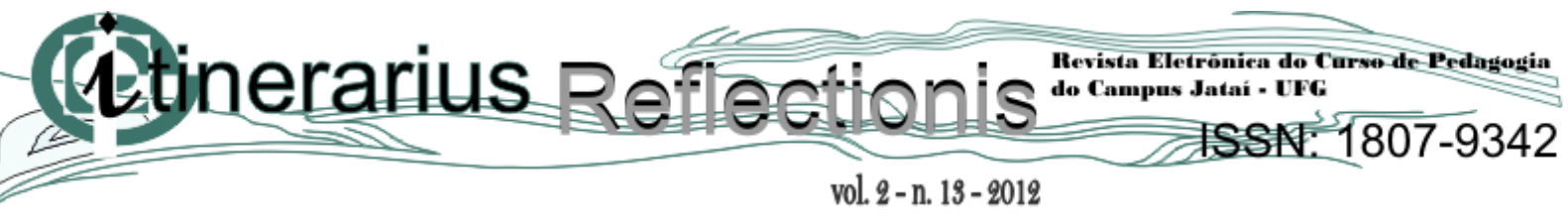

Viagem ao interior do corpo humano:

O Dr. Zoddi reuniu sua equipe que estava prontamente vestida com o traje adaptado para a viagem. Ele os acompanhou até a nave e ligou a máquina de redução, que encolheu todos os jogadores e os colocou em uma placa de Petri. O Dr. Zoddi os levou até sua mesa onde ele comia uma ração composta por alimentos de diversas naturezas e composições. Num descuido do cientista, todos os jogadores caíram dentro da ração e foram engolidos por ele.

A partir de agora os jogadores possuem um objetivo: sair do corpo do Dr. Zoddi intactos e vivos. Para o cumprimento de tal missão, deverão responder corretamente aos desafios apresentados pelo mestre.

- Mestre: vocês estão na boca, sua nave não está pronta para decolar, para ter o direito de ligá-la, vocês podem responder a uma pergunta ou tirar a sorte no dado. Caso optem pelo dado, um jogador com habilidade alta é quem deverá jogar o dado, ele deve por meio do cálculo tirar um valor maior que três (valor da habilidade menos o valor tirado no dado). Se optarem pela pergunta ou não conseguirem a sorte no dado, os jogadores devem responder:

Pergunta 1: qual a função da mastigação?

Respondido corretamente, a nave é ligada, caso contrário, eles morrem esmagados.

- Mestre: vocês ligaram a nave agora e devem seguir até a garganta, mas cuidado, a mastigação pode avariar sua nave, para passar pela boca vocês devem responder três perguntas. Cada resposta errada gera um dano à nave.

Pergunta 2: quais as glândulas que produzem a saliva?

Pergunta 3: quais as funções da saliva?

Pergunta 4: qual a função da língua? 
- Mestre: caso errem todas as respostas, todos morrem. Acertando ao menos uma, passam para a faringe, mas para seguir devem responder:

Pergunta 5: qual a função da epiglote?

- Mestre: no caso de errarem o Dr. Zoddi engasga e morre e o mesmo acontece com os jogadores. Caso a resposta esteja correta, seguem para o esôfago e respondem:

Pergunta 6: qual a função do esôfago? Qual o tipo de movimento que conduz o alimento para o estômago?

- Mestre: certa ou errada seguem para o esfíncter esofágico inferior, para prosseguirem para o estômago respondem:

Pergunta 7: qual a função de um esfíncter?

- Mestre: certa ou errada a resposta segue até o estômago. Uma forte onda peristáltica atingiu sua nave e vocês adentraram o estômago, seu conteúdo está ácido e vocês devem ligar os painéis de proteção da nave ou serão destruídos. Para ligar podem tentar o dado ou responder à pergunta. $\mathrm{O}$ jogador com maior habilidade joga o dado, pelo cálculo o valor deve ser maior ou igual a três (habilidade menos dado). Caso não obtenham sucesso no dado respondem:

Pergunta 8: quais as funções do estômago?

- Mestre: correta a resposta, a nave é protegida e os jogadores prosseguem em sua jornada. Caso a resposta seja incorreta, os jogadores são esmagados pelas contrações gástricas e sua nave é corroída pelo ácido. Com a resposta correta, para avançar na aventura devem responder:

Pergunta 9: quais enzimas compõem o suco gástrico?

Pergunta 10: qual o ácido presente no estômago? 


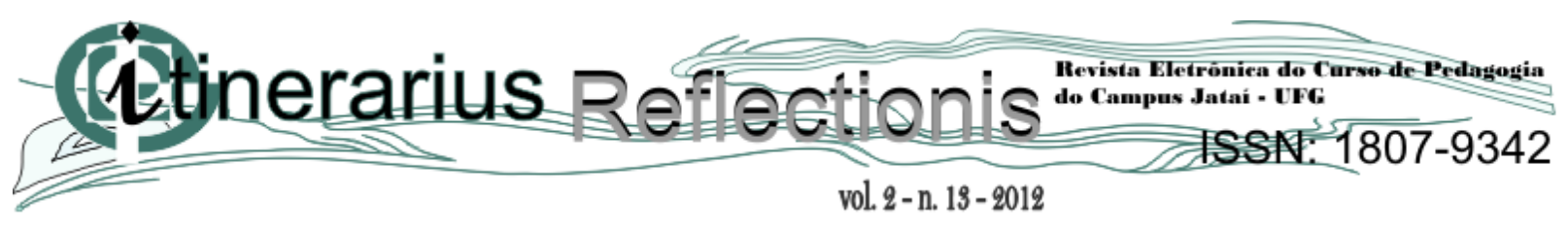

Durante as respostas o mestre faz pressão nos jogadores, dizendo, por exemplo, que a acidez está aumentando, aumentando...

Uma resposta certa permite a passagem para o intestino delgado, todas erradas eles morrem.

- Mestre: ao passar pelo piloro, a acidez vinda do estômago pode danificar o intestino do Dr. Zoddi. Porém, isso não acontece, pois uma substância é secretada na porção anterior do intestino delgado (duodeno) que tampona a acidez. Para os jogadores prosseguirem devem responder à questão.

Pergunta 11: qual é a substância liberada no duodeno que diminui a acidez proveniente do estômago?

O mestre pode responder esta questão caso os jogadores não consigam.

- Mestre: agora vocês devem ir ao mini-laboratório da nave e produzir uma substância semelhante à secreção pancreática rica em bicarbonato. Só poderão ir ao laboratório os jogadores que possuem maiores pontos em responsabilidade, inteligência e habilidade. Deverá ficar no controle da nave aquele com maiores pontos em calma. Agora que vocês chegaram ao laboratório devem responder as perguntas para garantir a produção do bicarbonato, caso errem a missão falha.

Pergunta 12: quais os elementos químicos que compõem a secreção pancreática?

Pergunta 13: além das secreções do pâncreas, que órgão associado ao sistema digestório produz a bile?

Pergunta 14: que substâncias compõem os sucos biliares?

- Mestre: com as respostas corretas vocês produzem a substância e liberam a nave. Errando, a missão falha pela destruição do duodeno e o jogo termina. Caso haja continuação do jogo, os jogadores que estão na direção da nave, que agora está sendo obstruída pelo 
vol. 2-n. 13-2012

quimo, devem responder perguntas para liberar a passagem da nave e seguir para o próximo passo. Seu erro acabará por encalhar a nave.

Pergunta 15: para que servem as vilosidades intestinais?

Pergunta 16: quais enzimas são liberadas pelo pâncreas?

Pergunta 17:quais as ações da amilase sobre os carboidratos?

- Mestre: com as respostas certas ou erradas vocês seguem e encalham na junção do intestino delgado com o grosso. Para desencalhar da nave todos devem vestir seus trajes especiais e descer da nave. Na luz do tubo vocês podem responder às perguntas ou tentar a sorte no dado. Optando pelo dado o jogador com maior força devera lançar o dado e pelo cálculo, força menos dado, tirar um número maior que quatro. Conseguindo atravessam a válvula ileocecal seguem para o Intestino Grosso.

Caso não tirem a sorte nos dados, respondem:

Pergunta 18: quais as funções do jejuno e do íleo?

Pergunta 19: existem dois tipos de contrações no sistema digestório, quais são elas?

Pergunta 20: qual a função das ondas peristálticas?

O mestre pode ajudar na resposta.

- Mestre: parabéns, vocês conseguiram, agora devem voltar à nave, e seguir sua viagem. Vocês precisam de mais propulsão para subir pelo cólon ascendente do intestino grosso. Podem responder a uma pergunta ou tirar a sorte no dado. Pelo dado o jogador com maior pontuação em sorte deve tirar 2 ou mais. Não conseguindo respondem:

Pergunta 21: qual a função do apêndice vermiforme?

O mestre pode ajudar na resposta.

- Mestre: subam com rapidez pelo cólon ascendente até o transverso. Mas, tenham cuidado, pois várias bactérias estão atingindo sua nave. Para sair deste obstáculo vocês devem 
ligar suas armas, para isso devem tirar no dado 2 pontos. Isso deve ser feito pelo jogador mais azarado.

Em caso de número menor o mestre deve liberar o uso das armas.

- Mestre: o muco do intestino delgado desestabilizou sua nave e vocês caíram no cólon descendente. Se não diminuírem sua velocidade, vão se despedaçar. Para isso devem acionar os propulsores de estabilidade, respondendo:

Pergunta 22: intestino grosso possui vilosidades?

Pergunta 23: quais processos fisiológicos ocorrem no intestino grosso?

O mestre deve ajudar se necessário.

- Mestre: seus propulsores foram ligados e agora vocês estão no reto. O cheiro não está nada agradável! Para saírem o mais rápido daí devem responder às questões para atravessar os esfíncteres do ânus.

Pergunta 24: o esfíncter interno tem composição muscular diferente do externo, qual é?

Pergunta 25: o que causa o relaxamento dos esfíncteres anais internos e externos?

- Mestre: parabéns vocês saíram do corpo do Dr. Zoddi e por sorte todas as câmeras da nave filmaram a viagem. A partir de agora vocês serão reconhecidos por serem os primeiros a conhecer a digestão por inteiro.

Avaliação do jogo pela turma de Ciências Biológicas

A avaliação do jogo foi realizada primeiramente por meio de conversa informal com os estudantes da disciplina de Fisiologia Humana Básica, turma 2010, na qual foi aplicado o método, a fim de relatar suas impressões sobre o jogo e dar sugestões de como ele deve ser aplicado. 


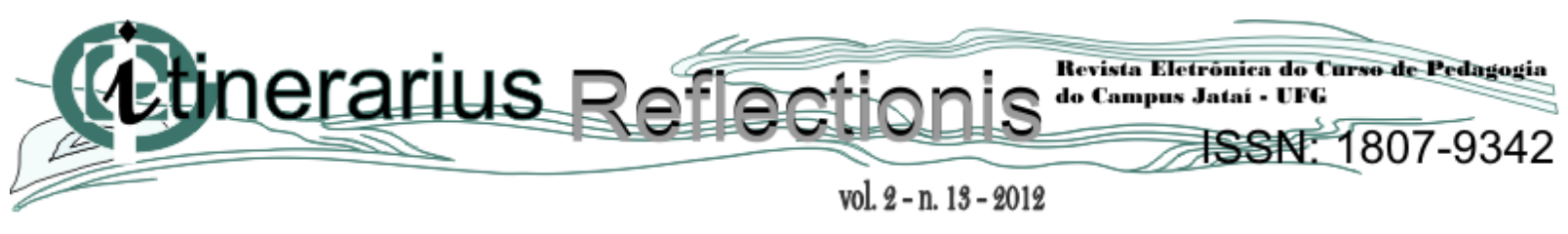

Os alunos demonstraram grande interesse pelo jogo e motivação com o conteúdo abordado durante a prática e, de forma geral, aprovaram o modelo didático. Os futuros educadores perceberam sua eficácia ao unir a estimulação da imaginação, o estímulo à cooperação no trabalho em grupo e a forma como pode ser utilizado tanto para ensinar como para avaliar os conhecimentos adquiridos.

Uma possível dificuldade relatada pelos estudantes para sua aplicação no ensino básico seria a quantidade de alunos por sala de aula e o tempo gasto para o desenvolvimento do jogo, pois o número de alunos por rodada deve ser de no máximo cinco e o jogo teve duração de trinta minutos aproximadamente. Assim, é possível que os professores não disponham de tanto tempo para aplicar o jogo diversas vezes com a mesma turma em uma aula. Uma sugestão para a solução deste problema foi o treinamento de outros alunos para exercerem a função de mestre. Assim poderiam ser formados vários grupos para o e o professor seria um fiscal ou um "mestre dos mestres" que ficaria percorrendo e avaliando os trabalhos dos vários grupos.

Alternativa sugerida para que o professor utilize o RPG com turmas grandes seria a elaboração de uma apresentação de slides em multimídia, configurada de modo que ao clicar em alternativas, o aluno seja levado automaticamente ao novo desafio, assim o professor pode aplicar dentro do laboratório de informática a todos os alunos de uma só vez.

Avaliação do jogo pelos estudantes do ensino fundamental e médio

No Ensino Médio o jogo dependeu do treino de vários mestres e da aplicação simultânea em vários grupos e com um "mestre dos mestres".

Ao término do jogo, os alunos relataram sobre suas impressões a respeito da prática e responderam a três questões:

1) Como você avalia este jogo?

2) Para você, este jogo lhe ajudou a aprender sobre a digestão? Por quê?

3) Relate o que você achou mais interessante e o que você achou menos interessante com este jogo. 


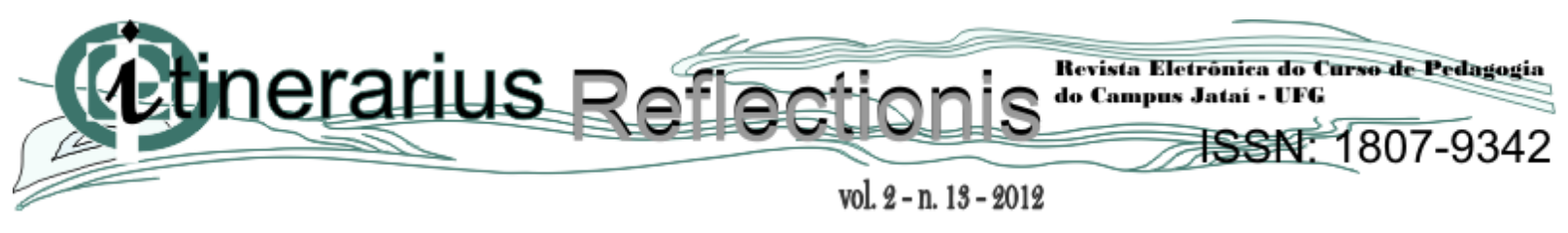

Era de se esperar uma grande aceitação do jogo na sala de aula, pois ele retirou o aluno da rotina de aulas expositivas, portanto as respostas referentes à questão um giraram em torno do ótimo/bom. Destaca-se também o relato dos estudantes de maior participação (ou participação ativa) durante a aula, de maior interação com os colegas e a relação da vitória no jogo dependente de seu esforço e da cooperação no decorrer do jogo

Quanto à segunda questão, ocorreu a predominância da resposta de que o jogo os auxiliou a "aprender", o que nos mostra como o RPG pode ser utilizado para ensinar sobre o conteúdo e não apenas para avaliar a aprendizagem.

$\mathrm{Na}$ terceira questão notamos o envolvimento dos alunos com a história do jogo em respostas como "o menos interessante foi sairmos pelo bolo fecal... eca!", ou "o planeta ter sido destruído". Entretanto, alguns alunos perceberam o objetivo didático do jogo e enalteceram sua função educativa.

Em entrevista com os alunos-mestres, percebemos que seria necessário um tempo maior para treinamento, pois somente alguns minutos antes do início do jogo não foi suficiente.

\section{Considerações finais}

Consideramos que o jogo de RPG educativo elaborado no presente trabalho atingiu o objetivo de criar um modelo didático para o ensino por métodos lúdicos, auxiliando na aprendizagem do conteúdo aplicado e na sua avaliação. O RPG em sala de aula pode ser importante instrumento para motivar o aluno a aprender, para cooperar em prol de um objetivo maior, melhorar a comunicação verbal e para estimular o aluno a adquirir conhecimentos com a finalidade de vencer objetivos. Ressaltamos que o esquema geral do jogo pode ser aplicado em qualquer disciplina e com qualquer conteúdo, uma vez que basta criar um desafio condizente com o conteúdo. 


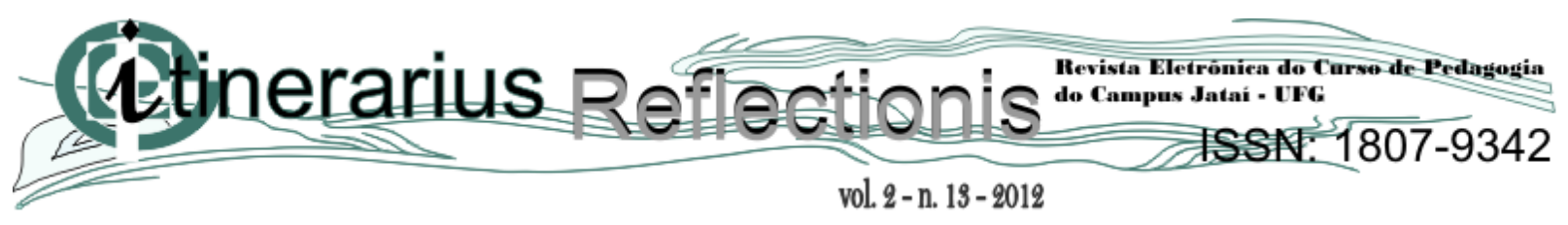

De acordo com Rezende \& Coelho (2009), apesar das dificuldades perante o trabalho educativo, é importante o rompimento do desânimo proporcionado pela passividade imposta pela escola. A quebra do "desânimo" foi percebida quando ao aplicarmos o jogo no Ensino Fundamental, alguns alunos resistiram de início a participar do jogo, mas posteriormente tornaram se interativos dentro da atividade.

Segundo Moratori (2003), os educadores possuem dificuldade em aplicar jogos em sala de aula, por causa da necessidade anterior de planejamento e a compatibilidade com a carga horária executada por professores da rede pública. Entretanto, como o uso de jogos pode ser avaliativo, revisor, introdutório ou reforçador do conteúdo aplicado, é uma importante estratégia a ser implementada na prática profissional, podendo incluir os próprios estudantes no processo de elaboração dos jogos. Apesar disso, consideramos que o uso constante do jogo deve ser ponderado pelo professor, pois o impacto causado por ele pode ser decorrente de sua inconstância.

\section{REFERÊNCIAS}

AMARAL, Ricardo Ribeiro do. O uso pedagógico do RPG para o ensino de Física. Dissertação (mestrado em Ensino de Ciências) - Universidade Federal Rural do Pernambuco. Recife, 2008. Disponível em < http://pt.scribd.com/doc/32088015/USO-DO-RPGPEDAGOGICO-PARA-O-ENSINO-DE-FISICA-Ricardo-Ribeiro-do-Amaral-2008 > Acesso em 02 mai. 2011.

CABRERA, Waldirléia Baragatti. A Ludicidade para o ensino médio na disciplina de biologia: Contribuições ao processo de aprendizagem em conformidade com os pressupostos teóricos da Aprendizagem Significativa. Dissertação (Mestrado em Ensino de Ciências e Educação Matemática) - Universidade Estadual de Londrina, Londrina, 2006. Disponível em http://www.diaadiaeducacao.pr.gov.br/diaadia/diadia/arquivos/File/conteudo/artigos_teses/Bi ologia/Dissertacao/ludicidade.pdf > Acesso em 02 mai. 2011.

CAMPOS, Luciana Maria Lunardi; BORTOLOTO, T.M.; FELÍCIO, A. K. C. Produção de jogos didáticos para o ensino de ciências e biologia: uma proposta para favorecer a aprendizagem. Departamento de Educação - Instituto de Biociências da UNESP - Campus de Botucatu - São Paulo. Caderno dos Núcleos de Ensino, p. 35-48, 2003. Disponível em < http://www.unesp.br/prograd/PDFNE2002/aproducaodejogos.pdf > Acesso em 02 mai. 2011. 
FERREIRA, José Henrique Benedetti Piccoli et al. Aprendendo sobre a relação presapredador por meio de jogos pedagógicos. Departamento de Fisiologia - UNESP/ Instituto de Biociências/Botucatu - São Paulo, 2010. Disponível em < http://www.unesp.br/prograd/PDFNE2005/artigos/capitulo\%2010/aprendendopresapredador.p df > Acesso em 02 mai. 2011.

MAIKE, Vanessa Regina Margareth Lima; MIRANDA, Leonardo Cunha de; BARANAUSKAS, M. Cecília C. Investigando sobre Requisitos para um Jogo de RPG com Professores de uma Escola Pública de Ensino Fundamental. Anais do XXII SBIE - XVII WIE. Aracaju, 21 a 25 de novembro de 2011. Disponível em < http://www.br-ie.org/sbiewie2011/SBIE-Trilha3/93261_1.pdf > Acesso em 25 nov. 2012.

MORATORI, Patrick Barbosa. Por que Utilizar Jogos Educativos no Processo de Ensino Aprendizagem? Rio de Janeiro, dez. 2003. Disponível em < http://www.nce.ufrj.br/ginape/publicacoes/trabalhos/t_2003/t_2003_patrick_barbosa_morator i.pdf > Acesso em 25 nov. 2012.

REZENDE, Márcia; COELHO, Christiano Peres. A Utilização do Role-Playing Game (RPG) no Ensino de Biologia como Ferramenta de Aprendizagem Investigativo/Cooperativa. In: XXV CONADE, Congresso Nacional de Educação de Jataí CAJ/UFG. $\quad$ Jataí, $2009 . \quad$ Disponível em http://revistas.jatai.ufg.br/index.php/acp/article/viewFile/760/405 > Acesso em 25 nov. 2012. 